\title{
Preparation of Alkyl Formates from Corresponding Alcohols using Ethyl Formate Catalyzed by Poly(4-vinylpyridinium tribromide) under Neutral and Solvent-Free Conditions
}

\author{
Arash Ghorbani-Choghamarani* and Masoomeh Norouzi \\ Department of Chemistry, Faculty of Science, Ilam University, P.O. Box 69315516, Ilam, Iran \\ *E-mail: arashghch58@yahoo.com; a.ghorbani@mail.ilam.ac.ir \\ Received January 15, 2011, Accepted February 21, 2011
}

Key Words : Alcohols, Alkyl formate, Formylation, Poly(4-vinylpyridinium tribromide), Ethyl formate

The introduction and development of heterogeneous catalysts for fine chemical synthesis has become a major area of research. ${ }^{1}$ Also important aspect of clean technology is the use of environment-friendly catalysts. ${ }^{2}$

Formylation of the hydroxyl group is of great interest because of its importance in organic synthesis, which provides an efficient method for the protection of $\mathrm{OH}$ groups. A variety of literature methods were examined for this transformation such as $\mathrm{HCOOH} / \mathrm{SiO}_{2},{ }^{3}\left(\mathrm{NH}_{4}\right)_{8}\left[\mathrm{CeW}_{10} \mathrm{O}_{36}\right] \cdot 20 \mathrm{H}_{2} \mathrm{O} /$ ethyl formate, ${ }^{4}$ sulfuric acid ([3-(3-silicapropyl)sulfanyl]propyl)ester/ethyl formate, ${ }^{5}$ [bmim $] \mathrm{HSO}_{4} /$ ethyl formate, ${ }^{6}$ silica sulfuric acid/ethyl formate, ${ }^{7} \mathrm{HCOOH} /$ silica triflate, ${ }^{8}$ $\mathrm{K}_{2} \mathrm{CO}_{3} /$ chloral, ${ }^{9} \mathrm{Mg}\left(\mathrm{HSO}_{4}\right)_{2} / \mathrm{HCOOH}^{10}{ }^{10}$ 2,2,2-trifluoroethyl formate, ${ }^{11} \mathrm{PPh}_{3} / \mathrm{CBr}_{4} /$ ethyl formate, ${ }^{12} \mathrm{~K}_{5} \mathrm{CoW}_{12} \mathrm{O}_{40} \cdot 3 \mathrm{H}_{2} \mathrm{O}$ / ethyl formate. ${ }^{13}$ However most of these procedures suffer from one or more of the following drawbacks: harsh reaction conditions, long reaction times, low yields of products, heavy metal contamination, acidic media (which is not suitable for acid sensitive substrates and side reaction.

Therefore to improve above-mentioned limitation we decided to use non-acidic catalyst and neutral conditions for the preparation of alkyl formates.

In continuing of our experiments on the application of new reagents or reagent systems in the organic functional group transformations ${ }^{14-22}$ we became interested to prepare alkyl formates from the corresponding alcohols in the presence of a neutral catalyst. Recently we have introduce a new tribromide reagent (poly(4-vinylpyridinium tribromide), as

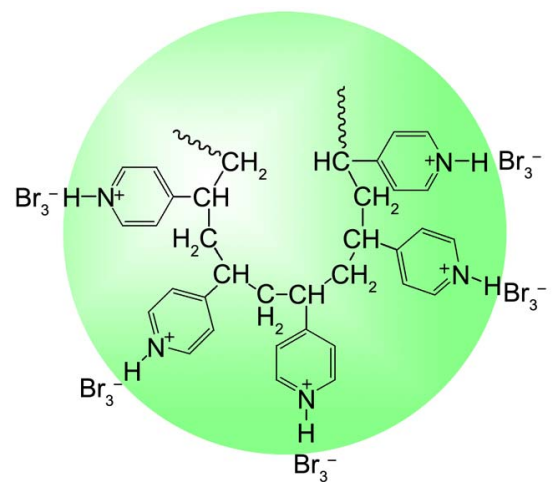

Figure 1. Poly(4-vinylpyridinium tribromide). green and none-toxic polymeric reagent (Fig. 1); ${ }^{23}$ therefore to investigate the scope and limitation of this reagent we decided to apply poly(4-vinylpyridinium tribromide) as neutral and effective catalyst in the formylation of alcohols with ethyl formate.

Initially, in order to find appropriate conditions 4-fluorobenzyl alcohol was subjected to formylation reaction in different solvents but reaction didn't complete after 24 hours under solvent conditions. The results for solvent screening are summarized in Table 1.

Interestingly we observed that formylation reaction for the 4-fluorobenzyl alcohol completed within $50 \mathrm{~min}$ in $91 \%$ yield. Eventually, we decide to carry out the formylation reaction in the absence of the solvent (i.e. solvent-free conditions) for the all reactions.

Consequently, a wide variety of alcohols were converted into corresponding alkyl formates using ethyl formate in the presence of a catalytic amount of poly(4-vinylpyridinium tribromide) at room temperature under solvent-free condi-

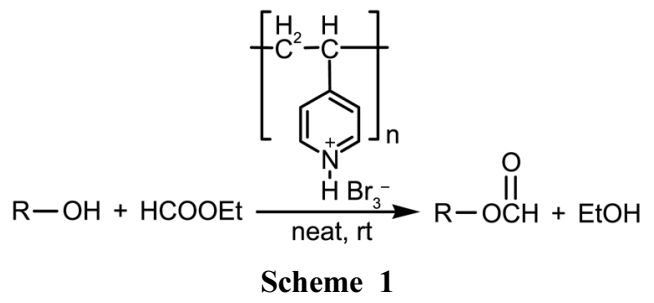

Table 1. Formylation of 4-fluorobenzyl alcohol using ethyl formate in the presence of a catalytic amount of poly(4-vinylpyridinium tribromide) at room temperature in the different solvents ${ }^{a}$

\begin{tabular}{cccc}
\hline Entry & Solvent & Time $(\mathrm{h})$ & ${\text { Yield }(\%)^{\mathrm{b}}}^{\mathrm{b}}$ \\
\hline 1 & Acetone & 24 & 38 \\
2 & Chloroform & 24 & 31 \\
3 & Dichloromethane & 24 & 35 \\
4 & $n$-Hexane & 24 & 58 \\
5 & Ethyl acetate & 24 & 71 \\
6 & Acetonitrile & 24 & 40 \\
7 & No solvent & 50 min & 91 \\
\hline
\end{tabular}

${ }^{a}$ Substrate : Ethyl formate : Catalyst : solvent for entries 1-6 (1 mmol : 2 $\mathrm{mmol}: 0.035 \mathrm{~g}: 5 \mathrm{~mL})$; for entry $7(1 \mathrm{mmol}: 2 \mathrm{~mL}: 0.035 \mathrm{~g}: 0 \mathrm{~mL})$. ${ }^{b}$ Isolated yield (product purified by short column chromatography). 
Table 2. Formylation of alcohols using ethyl formate $\mathbf{I}$ in the presence of a catalytic amount of poly(4-vinylpyridinium tribromide) II at room temperature under neat conditions

\begin{tabular}{|c|c|c|c|c|c|c|}
\hline \multirow{2}{*}{ Entry } & \multirow{2}{*}{ Substrate } & \multirow{2}{*}{ Product } & \multicolumn{2}{|c|}{ Substrate/Reagents ${ }^{a}$} & \multirow{2}{*}{ Time (Min) } & \multirow{2}{*}{ Yield (\%) } \\
\hline & & & $\mathrm{I}$ & II & & \\
\hline 1 & & & 2 & 0.052 & 60 & 69 \\
\hline 2 & & & 2 & 0.035 & 40 & 96 \\
\hline 3 & & & 2 & 0.035 & 50 & 91 \\
\hline 4 & & & 2 & 0.035 & 90 & 66 \\
\hline 5 & & & 2 & 0.035 & 50 & 92 \\
\hline 6 & & & 2 & 0.035 & 45 & 90 \\
\hline 7 & & & 2 & - & $24 \mathrm{~h}$ & Trace $^{c}$ \\
\hline 8 & & & 2 & 0.035 & 130 & 95 \\
\hline 9 & & & 2 & 0.035 & 90 & 70 \\
\hline 10 & & & 2 & 0.035 & 135 & 82 \\
\hline 11 & & & 2 & 0.035 & 65 & 83 \\
\hline 12 & & & 2 & 0.052 & 100 & 58 \\
\hline 13 & & & 2 & 0.035 & 90 & 69 \\
\hline 14 & & & 2 & 0.035 & 120 & 96 \\
\hline 15 & & & 2 & 0.035 & 180 & 53 \\
\hline 16 & & & 2 & 0.035 & 180 & 92 \\
\hline 17 & & & 2 & 0.052 & 90 & 64 \\
\hline 18 & & & 2 & 0.035 & 100 & 94 \\
\hline 19 & & & 2 & 0.035 & 110 & 44 \\
\hline 20 & & & 2 & 0.035 & $30 \mathrm{~h}$ & 89 \\
\hline 21 & & & 2 & 0.035 & 120 & 76 \\
\hline 22 & & & 2 & 0.035 & $24 \mathrm{~h}$ & No R. \\
\hline 23 & & & 2 & 0.035 & $24 \mathrm{~h}$ & $-^{d}$ \\
\hline 24 & & & 2 & 0.035 & $24 \mathrm{~h}$ & No R. \\
\hline
\end{tabular}

$\overline{{ }^{a} \mathbf{I} \text { refers to } \mathrm{mL} \text { of ethyl formate and II refers to gram of the catalyst. }{ }^{b} \text { Isolated yield (product purified by short column chromatography). }{ }^{c} \text { Reaction }}$ proceeds in the absence of the catalyst. ${ }^{d}$ Reaction didn't complete (conversion is $\approx 20 \%$ ) 


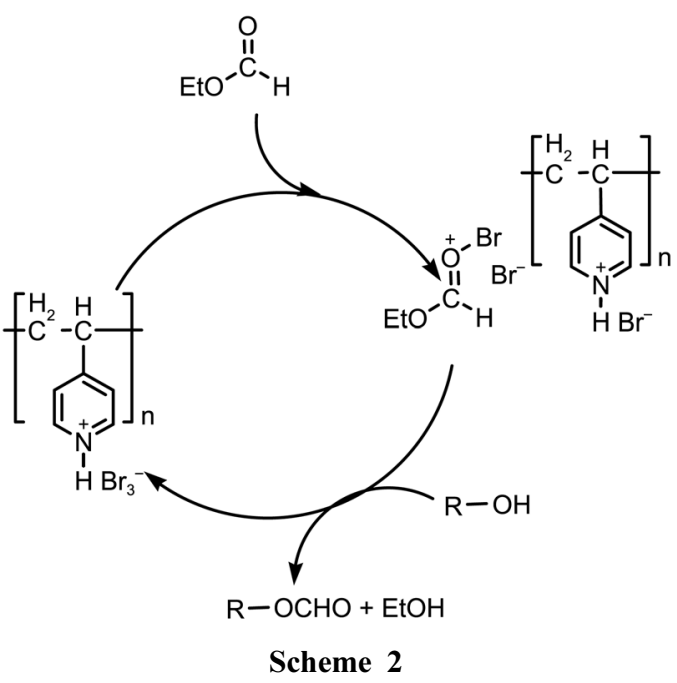

tions (Scheme 1). The results of this transformation including molar ration of the reaction components, reaction times and product yields are summarized in Table 2 .

Formylation of alcohols selectively proceed under mild conditions and any attempt to prepare formylated phenols and thiols (Table 2, entries 22, 24) was failed. Also formylation of aniline, as representative of amines, only produced $\approx 20 \%$ of $N$-formyl aniline.

In order to investigate the catalytic role of poly(4vinylpyridinium tribromide), 4-tert-butylbenzyl alcohol was subjected to formylation reaction in the absence of this compound. Interestingly, only trace conversion of product was observed after $24 \mathrm{~h}$ (entry 7), while in the presence of catalyst the same reaction completed within $45 \mathrm{~min}$ in $90 \%$ yield (Table 2, entry 6).

Suggested mechanism for this transformation is outlined in Scheme 2, based on our previously experience on tribromide $^{21,23}$ and $N$-halo reagents. ${ }^{24-27}$

Poly(4-vinylpyridinium tribromide) acts as a source of $\mathrm{Br}^{+}$, which coordinates with oxygen of carbonyl group in ethyl formate to produce active formylating agent. Then a nucleophilic attack of hydroxyl group on the carbonyl group followed by elimination of ethanol gives alkyl formate.

To show the efficiency of the described system in comparison with previously reported procedures in the literature, we compared our obtained results for the preparation of 4nitrobenzyl formate (as a typical example) with the best of the well-known data from the literature as shown in the Table 3 .
In summary, herein we introduced poly(4-vinylpyridinium tribromide as neutral catalyst for the conversion of alcohols into alkyl formates using ethyl formate. The advantages of this procedure are the avoidance of metallic and acidic catalysts, organic solvents, corrosive and toxic reagents and operational simplicity.

\section{Experimental}

General. Chemicals were purchased from Fluka, Merck and Aldrich chemical companies. The formylated products were characterized by comparison of their spectral (IR, ${ }^{1} \mathrm{H}$ $\mathrm{NMR}$, and $\left.{ }^{13} \mathrm{C} \mathrm{NMR}\right)$ and physical data with authentic samples. Poly(4-vinylpyridinium tribromide) was prepared via our previously reported procedure. ${ }^{23}$

Formylation of 4-Fluorobenzyl Alcohol using Ethyl Formate Catalyzed by Poly(4-vinylpyridinium tribromide). To a $15 \mathrm{~mL}$ round-bottom flask 4-fluorobenzyl alcohol (1 mmol, $0.126 \mathrm{~g})$, ethyl formate $(2 \mathrm{~mL})$ and poly(4vinylpyridinium tribromide), $(0.035 \mathrm{~g})$ was added. This mixture was stirred at room temperature for $50 \mathrm{~min}$ (the reaction progress was monitored by TLC). After reaction completion, reaction mixture was passed on short column chromatography (packed by silica gel) using dichloromethane as eluent to obtain 4-fluorobenzyl formate in $91 \%$ yield $(0.140 \mathrm{~g})$.

Acknowledgments. Financial support for this work by the Ilam University, Ilam, Iran is gratefully acknowledged.

\section{References}

1. Likhar, P. R.; Roy, S.; Roy, M.; Subhas, M. S.; Kantam, M. L.; De, R. L. Synlett 2007, 2301.

2. Heravi, M. M.; Bakhtiari, K.; Oskooie, H. A.; Taheri, S. J. Mol. Catal. A-Chemical 2007, 263, 279.

3. Ghorbani-Vagheia, R.; Veisia, H.; Amiria, M.; Cheginia, M.; Karimia, M.; Akbari Dadamahaleha, S.; Sedrpoushan, A. S. Afr. J. Chem. 2009, 62, 39.

4. Mirkhani, V.; Tangestaninejad, S.; Moghadam, M.; Yadollahi, B.; Alipanah, L. Monatsh. Chem. 2004, 135, 1257.

5. Niknam, K.; Saberi, D. Appl. Catal. A-Gen. 2009, 366, 220.

6. Niknam, K.; Zolfigol, M. A.; Saberi, D.; Khonbazi, M. Chin. J. Chem. 2009, 27, 1548.

7. Zolfigol, M. A.; Chehardoli, G.; Dehghanian, M.; Niknam, K.; Shirinid, F.; Khoramabadi-Zad, A. J. Chin. Chem. Soc. 2008, 55, 885 .

8. Shirini, F.; Marjani, K.; Nahzomi, H. T.; Zolfigol, M. A. Phosphorus Sulfur Silicon Relat. Elem. 2007, 182, 1245.

9. Ram, R. N.; Meher, N. K. Tetrahedron 2002, 58, 2997.

Table 3. Comparison of the different methods used for the formylation of 4-nitrobenzyl alcohol using ethyl formate with different catalyst

\begin{tabular}{cccccc}
\hline Entry & Conditions & Catalyst & Time (Min) & Yield (\%) $^{a}$ & Reference \\
\hline 1 & Neat (rt) & Poly(4-vinylpyridinium tribromide) & 90 & 66 & This work \\
2 & Neat (rt) & Sulfuric acid ([3-(3-silicapropyl)sulfanyl]propyl)ester & 100 & 45 & 5 \\
3 & Neat (rt) & $\mathrm{Al}\left(\mathrm{HSO}_{4}\right)_{3}$ & 15 & 89 & 7 \\
4 & Neat (rt) & Silica-bonded $N$-propyl sulfamic acid & 120 & 35 & 28 \\
5 & Neat (Reflux) & $\mathrm{K}_{5} \mathrm{CoW}_{12} \mathrm{O}_{40} \cdot 3 \mathrm{H}_{2} \mathrm{O}$ & 20 & 92 & 13 \\
6 & Neat (Reflux) & {$\left[\right.$ bmim] $\mathrm{HSO}_{4}$} & 300 & 50 & 6 \\
\hline
\end{tabular}

${ }^{a}$ Isolated yield. 
10. Shirini, F.; Zolfigol, M. A.; Mallakpour, B. Rus. J. Org. Chem. 2005, 41, 625 .

11. Hill, D. R.; Hsiao, C. N.; Kurukulasuriya, R.; Wittenberger, S. J. Org. Lett. 2002, 4, 111

12. Hagiwara, H.; Morohashi, K.; Sakai, H.; Suzuki, T.; Ando, M. Tetrahedron 1998, 54, 5845.

13. Habibi, M. H.; Tangestaninejad, S.; Mirkhani, V.; Yadollahi, B. Tetrahedron 2001, 57, 8333 .

14. Zolfigol, M. A.; Amani, K.; Ghorbani-Choghamarani, A.; Hajjami, M.; Ayazi-Nasrabadi, R.; Jafari, S. Catal. Commun. 2008, 9, 1739.

15. Ghorbani-Choghamarani, A.; Chenani, Z.; Mallakpour, S. Synth. Commun. 2009, 39, 4264.

16. Ghorbani-Choghamarani, A.; Goudarziafshar, H.; Nikoorazm, M.; Yousefi, S. Lett. Org. Chem. 2009, 6, 335.

17. Ghorbani-Choghamarani, A.; Rezaei, S. J. Chin. Chem. Soc. 2009, $56,251$.

18. Habibi, D.; Zolfigol, M. A.; Safaiee, M.; Shamsian, A.; GhorbaniChoghamarani, A. Catal. Commun. 2009, 10, 1257.

19. Amani, K.; Zolfigol, M. A.; Ghorbani-Choghamarani, A.; Hajjami, M. Monatsh. Chem. 2009, 140, 65.
20. Ghorbani-Choghamarani, A.; Zolfigol, M. A.; Ayazi-nasrabadi, R. J. Braz. Chem. Soc. 2010, 21, 33 .

21. Ghorbani-Choghamarani, A.; Zolfigol, M. A.; Azadbakht, T. Phosphorous Sulfur Silicon Relat. Elem. 2010, 185, 573.

22. Ghorbani-Choghamarani, A.; Zeinivand, J. J. Iran. Chem. Soc. 2010 $7,190$.

23. (a) Ghorbani-Choghamarani, A.; Zolfigol, M. A.; Hajjami, M.; Darvishi, K.; Gholamnia, L. Collect. Czech. Chem. Commun. 2010, 75, 607. (b) Ghorbani-Choghamarani, A.; Abbasi, M. Chin. Chem. Lett. 2011, 22, 114.

24. Ghorbani-Choghamarani, A.; Amani, K.; Zolfigol, M. A.; Hajjami, M.; Ayazi-nasrabadi, R. J. Chin. Chem. Soc. 2009, 56, 255.

25. Ghorbani-Choghamarani, A.; Zolfigol, M. A.; Hajjami, M.; Jafai, S. J. Chin. Chem. Soc. 2008, 55, 1208.

26. Zolfigol, M. A.; Ghorbani-Choghamarani, A.; Hazarkhani, H. Synlett. 2002, 1002.

27. Zolfigol, M. A.; Khazaei, A.; Ghorbani-Choghamarani, A.; Rostami, A.; Hajjami, M. Catal. Commun. 2006, 7, 399.

28. Niknam, K.; Saberi, D. Tetrahedron Lett. 2009, 50, 5210. 